IRA-International Journal of Technology \& Engineering ISSN 2455-4480

Proceedings of the

International Conference on Science \& Engineering for Sustainable Development (2017)

Pg. no.237-247

Published by: Institute of Research Advances https://research-advances.org/index.php/IRAJTE

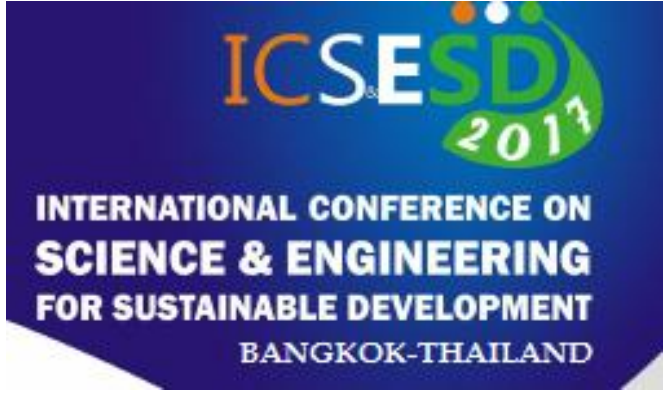

\title{
Experimental Investigation of Combustion Characteristics of Homogenous Charge Compression Ignition Engine
}

\author{
R. R. Chaudhari ${ }^{1}$, P. R. Gharde ${ }^{*^{2}}$ \\ ${ }^{1}$ HOD, Mech. Dept. Government Polytechnic, Nagpur, India. \\ ${ }^{2}$ Assistant Professor, Mech. Dept., Sinhgad Institute of Technology, Lonavala, India.
}

Type of Review: Originality Check \& Peer Review under the responsibility of the Scientific Committee of the Conference and The Institution of Engineers (India).

DOI: http://dx.doi.org/10.21013/jte.ICSESD201723

\section{How to cite this paper:}

Chaudhari, R., Gharde, P. (2017). Experimental Investigation of Combustion Characteristics of Homogenous Charge Compression Ignition Engine. Proceedings of the International Conference on Science \& Engineering for Sustainable Development (2017), 237-247. doi: http://dx.doi.org/10.21013/ite.ICSESD201723

(C) International Conference on Science \& Engineering for Sustainable Development\& The Institution of Engineers (India).

\section{(cc) BY-NC}

This work is licensed under a Creative Commons Attribution-Non Commercial 4.0 International License subject to proper citation to the publication source of the work.

Disclaimer: The conference papers as published by the Institute of Research Advances (IRA) are the views and opinions of their respective authors and are not the views or opinions of the IRA. The IRA disclaims of any harm or loss caused due to the published content to any party. 


\begin{abstract}
In diesel compression ignition engine, simultaneous reduction of NOx and PM is extremely challenging task. The most favorable solution for this is HCCI. It is an impulsive auto ignition of very lean air fuel mixture at multiple sites. It has advantages of both CI and SI engines. It also gives higher thermal efficiency like CI engines, higher ROHR, minimum DOC and has no flame propagation and mainly it has simultaneous control over NOx as well as PM. The combustion of homogeneous mixture in HCCI combustion helps in reducing DOC because of higher ROHR.

The present experiment is conducted on engine having two cylinders; they are made to operate on HCCI and conventional CI mode respectively. Both DI and PI systems were used simultaneously to investigate the performance characteristics. The toughest part is to prepare homogeneous mixture for combustion. As the diesel is a low volatile fuel, the preparation of homogeneous mixture is difficult therefore diesel vaporizer comes into picture. EGR is used to control the ROHR. To investigate the combustion characteristics experiment was performed at different relative air fuel ratios $(\lambda)$. The DOC and ROHR is increases with increasing $\lambda$. EGR dilutes the homogeneous mixture and leads to minimum NOx emission by keeping maximum temperature in cylinder low. The increased boost pressure is responsible for short DOC and high rate of combustion. Also the indicated mean effective pressure is improved by $3 \%$ by DI method as compared to PI in HCCI.
\end{abstract}

\begin{tabular}{|c|c|}
\hline \multicolumn{2}{|c|}{ ABBREVIATIONS } \\
\hline CI & Compression ignition \\
\hline SI & Spark ignition \\
\hline PM & Particulate mater \\
\hline $\mathrm{NO}_{\mathrm{x}}$ & Oxides of nitrogen \\
\hline DISI & Direct injection spark ignition \\
\hline IC & Internal combustion \\
\hline PI & Port injection \\
\hline DI & Direct injection \\
\hline EGR & Exhaust gas recirculation \\
\hline $\mathrm{HCCI}$ & $\begin{array}{l}\text { Homogeneous charge compression } \\
\text { ignition }\end{array}$ \\
\hline $\mathrm{CR}$ & Compression ratio \\
\hline DOC & Duration of combustion \\
\hline SOC & Start of combustion \\
\hline AHRR & Apparent heat release rate \\
\hline $\mathrm{IMEP}_{\text {gorss }}$ & $\begin{array}{l}\text { Gross indicated mean effective } \\
\text { pressure }\end{array}$ \\
\hline$\lambda$ & Relative air fuel ratio \\
\hline ATDC & After top dead center \\
\hline ROHR & Rate of heat release \\
\hline CA5 & $5 \%$ mass fraction burn point \\
\hline IVO & Inlet valve open \\
\hline EVC & Exhaust valve close \\
\hline CAD & Crank angle degree \\
\hline
\end{tabular}




\section{Introduction}

The pollutants quantity which can be released in atmosphere is limited by emission standard or emission norms. Any automobile cannot emit the pollutants above certain limit. Unlike conventional SI engine, DISI gasoline engines have better fuel economy and high performance. In this engine as the fuel can be stratified near the spark plug by DI, the flame can propagate and excess oxygen will be available around fuel under flammable limit for combustion. The NOx can be formed in the region of high temperature and PM can be formed near rich fuel region. If one wish to improve the efficiency, he have to deal with increasing NOx and on other hand if wish to reduce NOx, he have to face the problem of PM (1). In diesel engine as we go on increasing the combustion temperature the percent of NOx emitted increases and if we try to reduce the temperature the percent of PM increases this is the diesel dilemma. Hence reduction of both NOx and PM in diesel engine combustion is a big deal (2). The NOx emitted through IC engines causes the formation of photochemical smog and PM is responsible for many respiratory diseases (3). Also as we know the petroleum resources are limited, we should use it properly in order to save the fuel. So there is need of more improvement in combustion method in CI engines in order to improve the emission characteristics and fuel economy. Considering all these problems, the most effective and reliable technology by which we would have control over all parameters related to combustion is HCCI engine.

HCCI engine is favorable concept for upcoming future alternative combustion technology (4). The main advantage of HCCI engine is to occurring combustion of very lean and diluted premixed mixture of air and fuel simultaneously over multi-sites and producing higher ROHR without flame propagation (5). As it burns very lean and diluted mixture of air and fuel the resultant bulk temperature and localized combustion temperature will be lower. Due to which the NOx emission will be lower. Unlike the conventional CI engine combustion the mixture in HCCI engine is completely homogeneous. As there will not be fuel rich zones, the PM emission will also reduce to a great extent (3). HCCI engine provides higher efficiencies and low emission of NOx as well as PM compared to other conventional CI engines (6).

Onishi et al. found that for two stroke engines, spontaneous ignition leads to improve emission characteristics and fuel efficiency. For gasoline engine the stable HCCI combustion can be achieved for CR of 7:5:1 under low and high load limits (3). The diesel is low volatile fuel hence for diesel HCCI engines the preparation of homogeneous mixture was the major consideration. PI is the better way to form premixed homogeneous mixture of air and fuel. We can call it as external mixture formation technique. In this technique we provide sufficient temperature for fumigation of diesel to take place. With the help of greater intake air motion and temperature we can get completely homogeneous mixture of air and fuel for combustion (3).

NOx can be reducing by introducing EGR without consumption of excess fuel. EGR affects the bulk temperature, combustion rate, DOCand exhaust emission. EGR also responsible for dilution effects, thermal effects and chemical effects. As the temperature in HCCI combustion engine is lower, the chemical effects can be negligible with respect to that of dilution and thermal effects. Dilution of oxygen due to EGR results in retarding ignition and hot EGR results in advancing ignition (4). Lu et al. reported that by introducing EGR in HCCI combustion engine, first and second stage of combustion retards and overall DOC increases. 


\section{Experimental Set Up}

\section{Engine}

The experiments were performed on double cylinder, four stroke, air cooled CI engine. The combustion in HCCI and conventional diesel CI mode is happen in separate cylinders. The cooling air is supplied through circular casing of flywheel to cool the engine. The engine load can be altered by AC dynamometer. The cylinder pressure is measured by means of piezoelectric pressure transducer.

\section{Injection system}

The injection system consist fuel tank, pump, reservoir, injectors and injection control system. One fuel injector is placed at intake port for port fuel injection and another is mounted on cylinder head for direct injection. The fuel pump fitted into the fuel tank, pumps the fuel from tank to the reservoir. The injection control system controls SOI and DOI. TDC sensor provides the signals to injection control system to control SOI.

\section{Boost pressure system}

The device called as Turbocharger is used to increase the boost pressure of intake air. The turbocharger consists of turbine and compressor mounted on same shaft. The exhaust gas energy is used to rotate the turbine blades. As the turbine is connected with the same shaft that of compressor shaft, the rotation of turbine results in rotating compressor wheel. The intake air is passed through compressor which compresses the air and increases its pressure above atmospheric pressure. The boost pressure can be varied by turbocharger by waste gate.

\section{External Mixture formation system}

As the diesel is volatile in nature the formation of homogeneous mixture is too difficult. For this experiment diesel vaporizer is used to prepare homogeneous mixture of air and fuel. The vaporizer consists of copper vaporizing chamber cylindrical in shape; band heater is wrapped around the chamber. The heat required to vaporize the fuel is supplied by band heater. The fuel droplets sprayed in vaporization chamber by injector placed at intake port. They absorb latent heat of vaporization to atomize. The high pressure air from turbocharger mixes homogeneously with the vaporized fuel. This homogeneous mixture of air fuel is supplied to the engine cylinder.

\section{EGR system}

The experimental setup modified to EGR system, in which we supplying the part of exhaust gas back to the engine cylinder. The purpose of providing EGR is to minimizing the overall in cylinder combustion temperature to reduce NOx emission. The damper is inserted to minimize the exhaust gas pulsation. The amount of EGR can be controlled by EGR valve.

\section{Exhaust gas analysis system}

The measurement of NOx, PM, O2, $\mathrm{CO}$ and $\mathrm{CO} 2$ in the exhaust gas is done in Horiba gas analyzer. The contents of pollutants in exhaust are calculated by passing some exhaust gas to Horiba gas analyzer. 


\section{Data acquisition system}

The DAQ system consists of shaft encoder, TDC sensor, piezoelectric pressure transducer, temperature sensor, charge amplifier and DAQ board. The DAQ card of National Instrumentation is inbuilt in DAQ system. The function of piezoelectric pressure transducer is to sense the in-cylinder pressure and supply corresponding voltage signals to the DAQ system. The shaft encoder gives signals corresponding to crank angle (720 PPR). TDC sensor gives one signal every revolution on crank shaft when piston reaches TDC. All signals were passed to DAQ board through charge amplifier. All the analysis of combustion parameters is done in DAQ system and stored in computer.

\section{Present Work}

In present investigation, the study of combustion characteristics and performance of HCCI combustion technology with both DI and port fuel injection technique with external mixture formation is done $(3,6)$. Some modifications were made in conventional two-cylinder CI engine in order to achieve HCCI combustion. This paper also explores functional principles of diesel vaporizer. Various experiments were performed to study the performance and characteristics of combustion of HCCI engine under various loads, fuel strategies and EGR conditions $(3,4)$. The combustion characteristics were analyzed to improve $\mathrm{IMEP}_{\text {gross }}$ by varying injection timing and EGR rates.

\section{Result and Discussion}

The following experiment was performed by varying boost pressure, $\lambda$, EGR ratio, engine speed, engine loads and by altering injection system i.e. DI and PI.

Fig.1. shows the AHRR and cylinder pressures for different boost pressure when engine is running at different speed. From graph it is seen, by increase in boost pressure the SOC advances and peak cylinder pressure also increases. This is because; the faster combustion takes place as we go for higher boost pressure. Also with more boost pressure and engine speed, the DOC decreases (1).

The engine operating at two limits, namely knocking limit and misfire limit. At knocking limit the pressure rise is very high which cause excessive wear and at misfire limit there are more cyclic variation which cause decrease in heat release. Fig.2. shows, for different EGR condition and Relative air fuel ratio $(\lambda)$, what are the changes in cylinder pressure at different CAD. From graph it is seen that SOC takes place when pressure slope rises in motoring curve. As the $\lambda$ value decreases (mixture becomes richer) the SOC advances. This happens because more fuel is available at sufficient high temperature and pressure which helps for auto ignition of charge hence early SOC takes place. The SOC retarded and peak cylinder pressure decreases as we go on increasing EGR. The crank angle degree at which the peak cylinder pressure occur increases ATDC with EGR. This happens because EGR delay the combustion by diluting the mixture (3). The EGR rate is given by:

$$
E G R \%=\left(\frac{\left(\mathrm{CO}_{2} \%\right)_{\text {intake }}}{\left(\mathrm{CO}_{2} \%\right)_{\text {exhaust }}}\right) \times 100 \%
$$



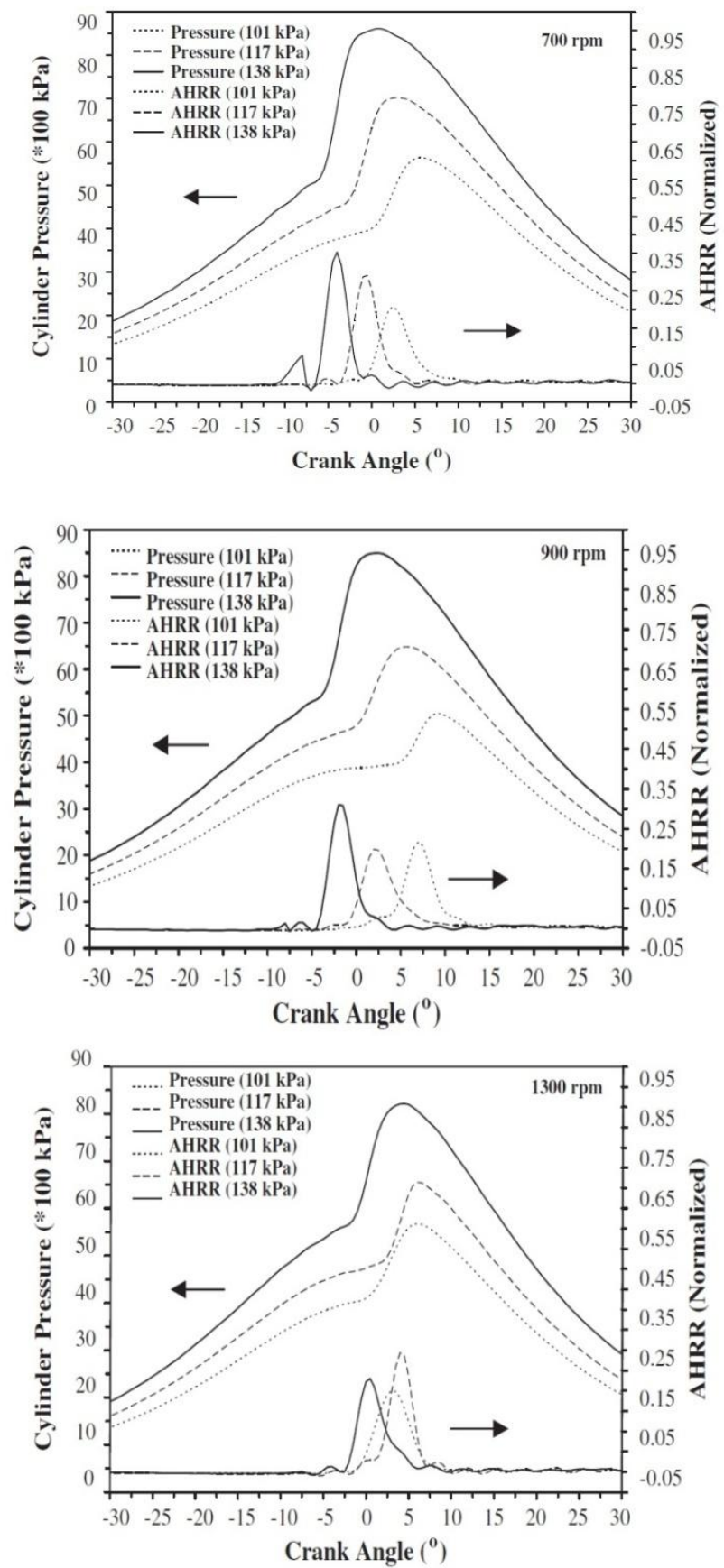

Fig.1. HRR and Cylinder pressure vs.CAD at different engine speed. 

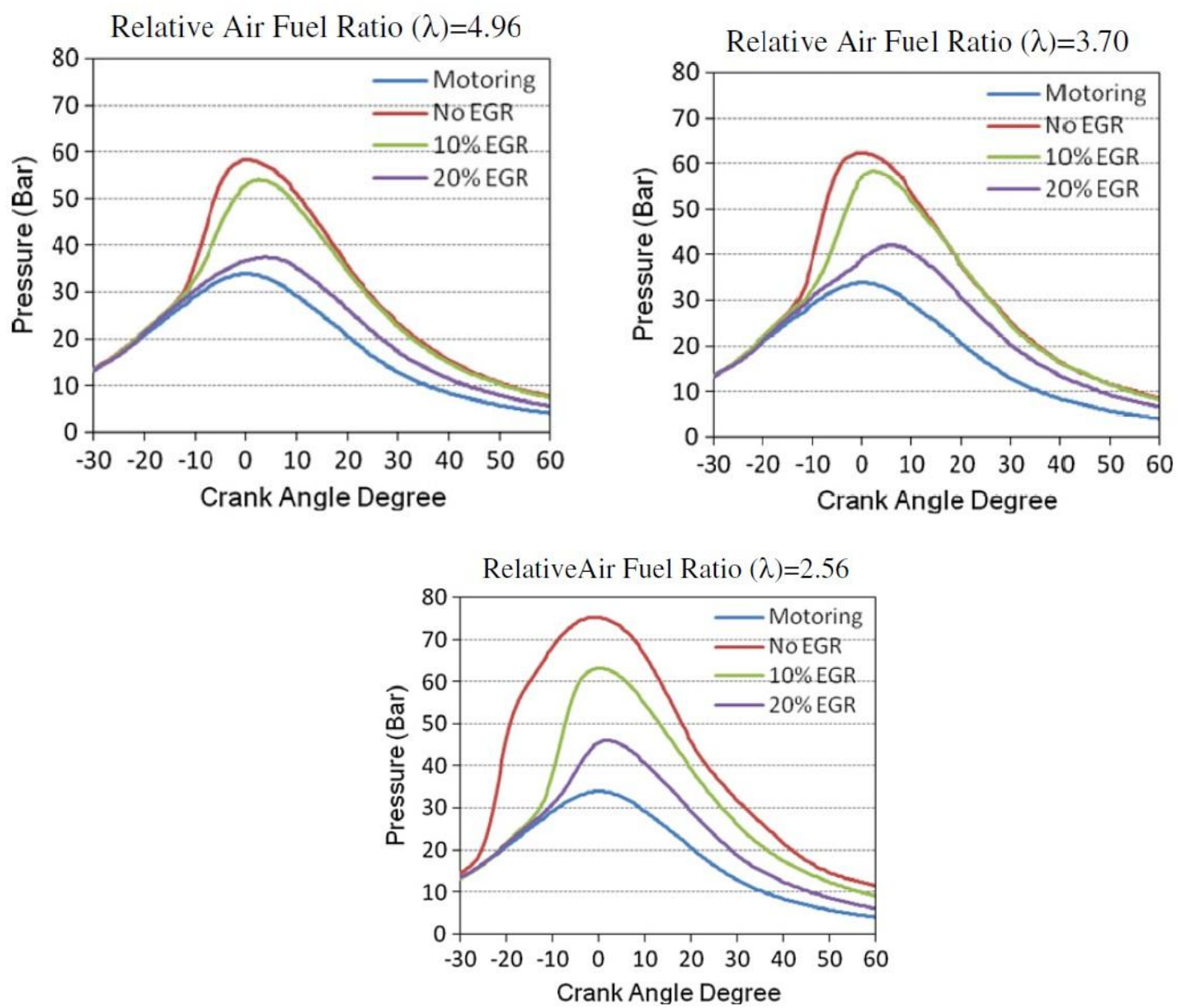

Fig.2. Variation in cylinder pressure at different EGR condition and Relative air fuel ratio $(\lambda)$.

Fig.3. shows the change in rate of heat release with CAD for different EGR condition and Relative air fuel ratio $(\lambda)$. This is determined by "zero dimensional heat release model" by cylinder pressure data. In HCCI combustion higher ROHR results difficulty in controlling the combustion rates. From graph it is seen that as $\lambda$ decreases the mixture becomes richer and ROHR increases. In HCCI we use EGR to control the combustion. It dilutes the mixture and reduces its reactivity. Hence from graph, as EGR increases the ROHR decreases by providing less reactive mixture for combustion (3).

Fig.4. shows variation in DOC with different Relative air fuel ratio $(\lambda)$ and EGR. From graph it is seen that DOC decreases with $\lambda$ because; mixture becomes richer by decreasing $\lambda$ which increases rate of combustion. Also DOC increases with EGR because; the reactivity of mixture reduces as EGR dilutes the mixture which results in slower combustion reaction (3).

To study the direct injection performance, IMEP gross and CA5 is compared with port injection. Fig.5. shows the variation of IMEP gross and CA5 with Relative air fuel ratio $(\lambda)$ for both DI and PI. The engine is running at $1000 \mathrm{rpm}$, IVO timing is 1 CAD ATDC, EVC timing is 6 CAD ATDC and injection timing is 20CAD. From fig. 5a it is seen that the maximum IMEP gross achieved when $\lambda$ is lower for both DI as well as PI. The IMEP gross increases as $\lambda$ decreases. The ignition timing is advanced and DOC reduces with reducing $\lambda$. The IMEP gross improved approximately by $3 \%$ with DI as compared to PI. CA5 represents the $5 \%$ mass fraction burned. From fig. $5 \mathrm{~b}$ it is seen that CA5 increases with $\lambda$ for both DI as well as PI. Also the CA5 occurs earlier for PI than DI because of temperature drop with DI (4). 

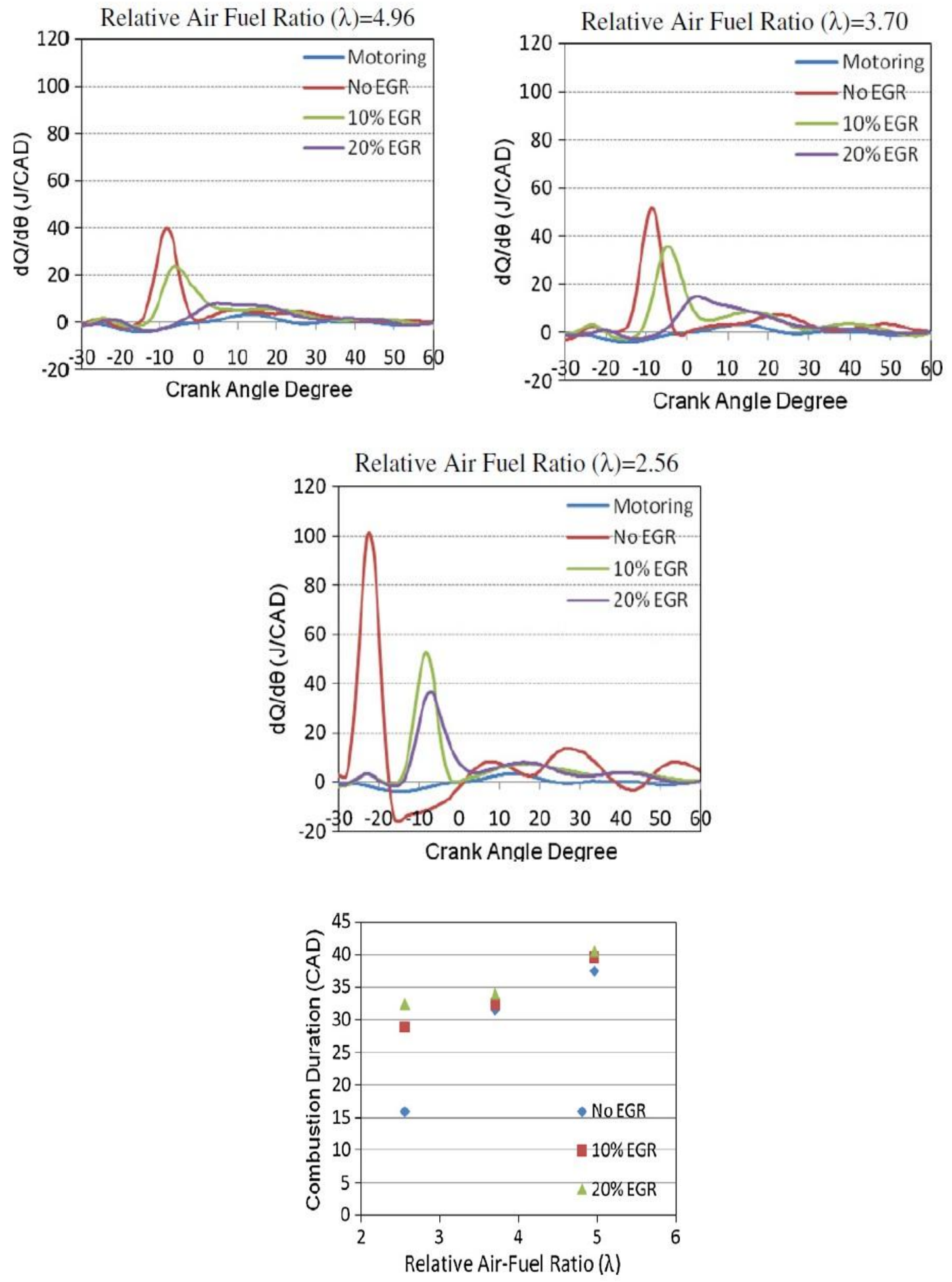

Fig.4. DOC for varying $\lambda$ and EGR. 

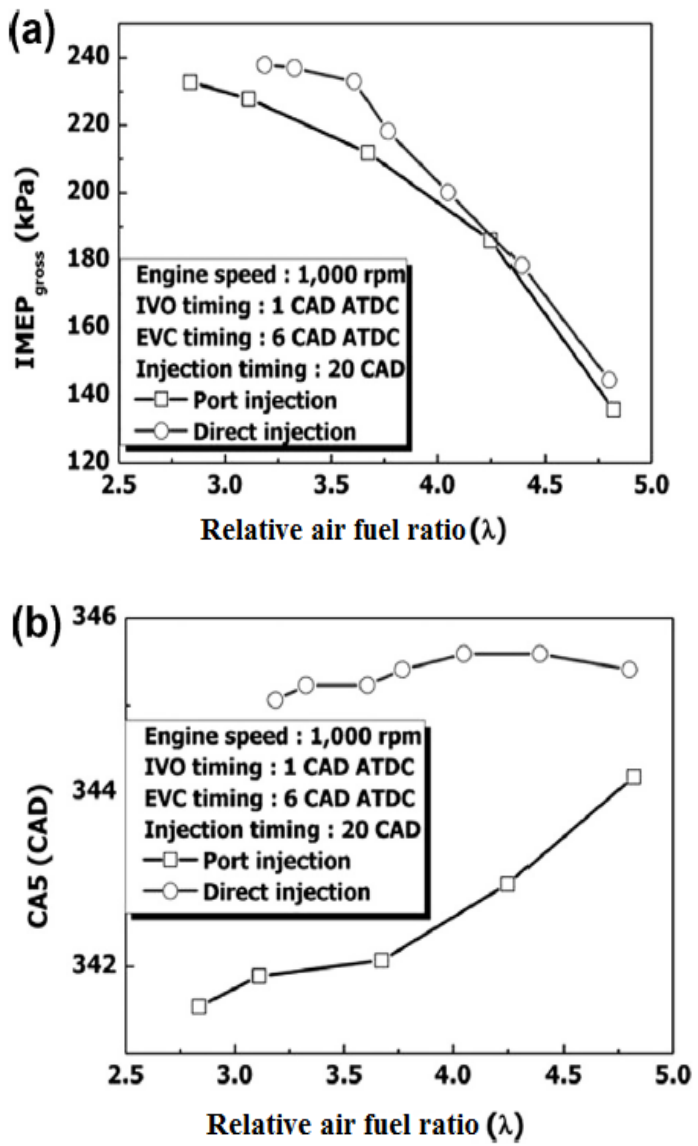

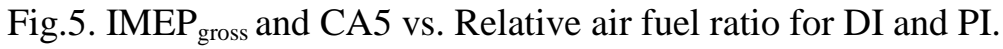

Fig.6. shows the change in brake thermal efficiency at different loads for three different conditions (Diesel vapor with 10\% EGR, Diesel vapor induction without EGR and Diesel fuel). From graph it is seen that with vaporized diesel fuel, brake thermal efficiency decreases. At constant load, say $75 \%$, the brake thermal efficiency reduced by $3.8 \%$ and $2.8 \%$ for diesel vaporization with no EGR and $10 \%$ EGR respectively. It is because of increase in fuel consumption because of continuous supply of fuel to vaporizer (6). 


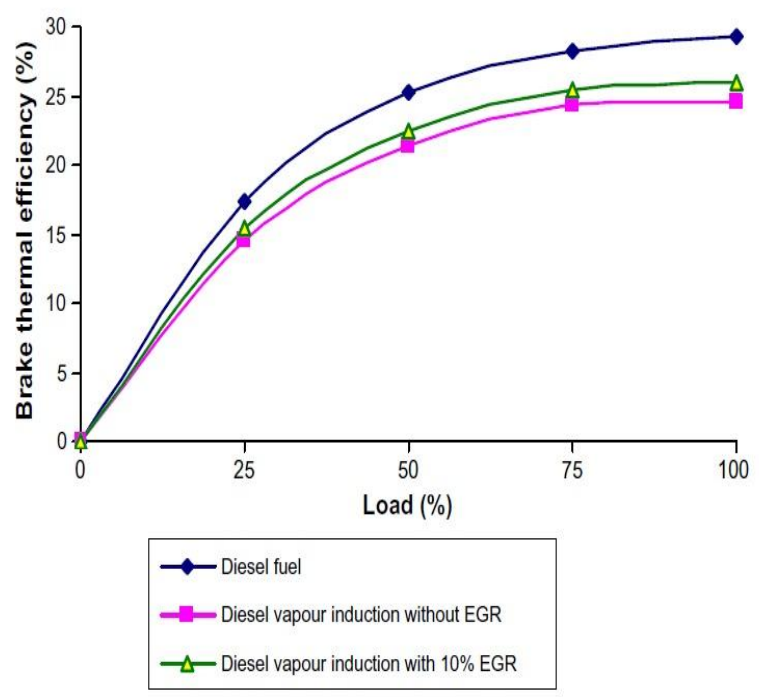

Fig.6. Brake thermal efficiency vs. engine load (for three different conditions).

\section{Conclusion}

The current investigation is done to understand the combustion and performance characteristics of diesel HCCI combustion engine under various parameters. The results were observed under different EGR conditions, boost pressures, $\lambda$, engine loads and for both DI and PI system. The results taken from several experiments were leads to following conclusion:

- External mixture formation method leads to give improved homogeneous charge for combustion.

- The peak cylinder pressure increases with boost pressure and the SOC advances as combustion rate goes on increasing.

- The DOC decreases with increase in boost pressure and engine speed and it is increases with increasing EGR and $\lambda$.

- Start of combustion advances as $\lambda$ decreases because of availability of more fuel. As EGR increases, SOC retarded and peak cylinder pressure decreases.

- ROHR is inversely proportional to $\lambda$ and EGR.

- For both direct and port injection system, at low $\lambda$ we get maximum IMEPgross.

- Compared to PI, IMEP gross is improved by approximately $3 \%$ with DI.

\section{References}

[1] Mustafa Canakci, Combustion characteristics of a DI-HCCI gasoline engine running at different boost pressures, Fuel 96 546-555 (2012).

[2] Ramesh A, Mallikarjuna J.M, Nathan S. Swami, Effects of charge temperature and exhaust gas re-circulation on combustion and emission characteristics of an acetylene fuelled HCCI engine, Fuel 89 515-521 (2010).

[3] K. Agarwal, Akhilendra P. Singh, Combustion characteristics of diesel HCCI engine: An experimental investigation using external mixture formation technique, Applied Energy 99 (2012) 116-125. 
[4] Lee Youngjae, Cho Chongpyo, Woo Youngmin, Ba Choongsik, J. Jinyoung, Improvement of DME HCCI engine combustion by direct injection and EGR, Fuel 113 (2013) 617-624.

[5] M. David Checkel, R. KhoshbakhtiSaray, MortezaFathi, Detailed approach for apparent heat release analysis in HCCI engines, Fuel 89 2323-2330 (2010).

[6] Ibrahim Mohamed M, Nagarajan G, Ganesh D, Study of performance, combustion and emission characteristics of diesel homogeneous charge compression ignition (HCCI) combustion with external mixture formation, Fuel 87 3497-3503 (2008). 